Primera parte Direito do Estado e Teoria do Direito 


\section{Direito Constitucional, Direito Ordinário, Direito JUDICIÁRIO}

\section{Cezar Saldanha Souza Junior}

\section{OORDENAMENTOJURÍDICO}

$O$ direito posto em um Estado assume a forma de ordenamento jurídico. Como escreveu BOBBIO, "as normas jurídicas não existem isoladamente, mas em um contexto de normas, com relações peculiares entre si". "Esse caráter do direito positivo é tão marcante que entre os sentidos comunicados pelo termo direito está, em primeiro lugar, o de ordenamento jurídico, como nas expressões direito brasileiro ou direito argentino. ${ }^{2}$ Sob esse ângrilo, direito e ordenamento jurídico são sinônimos.

Ainda segundo BOBBIO, o conceito de ordenamento jurídico denota algumas notas características. O orderxamento jurídico é: (a) unitário (forma um conjunto, uma unidade); (b) escalonado (as normas que o formam vêm dispostas em uma bierarquia, em planos de poderes e de deveres); (c) coerente (as normas jurídicas requerem barmonia, dai os critérios imaginados para resolver aparentes antinomias); e (d) completo (por dispor de meios para suptir eventuais lacuras). ${ }^{3}$ Em razão desse feixe de atributos, a doutrina construiu, de longa data, a noção de sistema jurídico.

1 BOBBIO, Norberto, A Teoria do Ordenamento Jurídico, Brasilia, UnB, 6ª Ed., p. 19.

3 Id., ib. .

3 Conferir op. cit, passim. 


\section{A INTUIÇÃO DE GEORG JELLINEK}

Foi no seio da cultura alemã que a ciência do direito elaborou a mais consistente teoria do ordenamento jurídico.

A intuição básica vem de GEORG JELLINEK, quando distinguiu duas funções jurídicas do Estado. Ou o Estado estabelece regras abstratas que, como tais, não regulam de modo imediato a realidade (mas exige uma atividade própria, motivada por essas regras abstratas, para realizar os fatos objetivos correspondentes). Ou o Estado atua de um modo imediato e direto quanto aos problemas que a ele competem (claro está, em conformidade com as nomas abstratas e dentro dos limites que elas the impõem). Daí segue que, segundo JELLINEK (Teoria Geral do Estado, Capítulo 18), o ordenamento jurídico apresenta dois degraus: (a) o das normas abstratas; e (b) o das normas individualizadas".

Entretanto, no Capítulo $8^{\circ}$, JELLINEK deixara entrever a existência de uma terceira instância, "reguladora da atividade política do Estado", superior àquelas duas, e por ele adjetivada de "última", ou dos "fins supremos", envolvendo um "juízo de valor teleológico". Tais "fins supremos" (...) "não afirmam o que haverá de suceder, mas aquilo que não há de ser feito". Cumprem uma "força reguladora negativa". Acrescenta que "essa influência negativa tem sido historicamente de um gtande valor e continuará sendo politicamente no futuro". E remata: "toda nossa cultura moderna descansa sobre a afirmaçăo de que os poderes do Estado têm um limite e de que nós não estamos submetidos, como escravos, ao poder ilimitado do Estado. ${ }^{5}$

\section{HANS KELSEN E A ESTRUTURA PIRAMIDAL DO ORDENAMENTO JURÍDICO}

Coube, porém, a KELSEN -como universalmente reconhecido- dar contornos rigorosos à teoria do escalonamento piramidal do ordenamento jurídico."

KEILSEN, porém, afastou completamente o caminho teleológico (que JELLINEK tentara abrit com sua visão dos fins do Estado). Voltou-se, exclusivamente, a um caminho lógico. Ou seja: o ordenamento jurídico em KELSEN é uma estrutura estritamente lógica, composta de três niveis hierárquicos?

(a) um grau superior ou fundamental do ordenamento jurídico, correspondendo às normas do topo da pirâmide, criadas pelo poder constituinte e que formam a Constituição do Estado;

4 JELLINEK, Georg. Teoria General del Estado. Buenos Aires, Abatroz, 1971, Cap. XVMI, p. 462.

Id., ib., Cap. VTII, p. 177 e 178.

"KELSEN, Hans. Teoria General del Derecho y del Estado. México, UNAM, 1969, pp. 147-161. Vero depoimento de BOBBIO, op. cit., p. 49.

3 KELSIN, Hans. Teoria Pura do Direito. Coimbra, Armênio Amado, $5^{\text {2 }}$ ed., 1979, pp. 309-327. 
(b) um grau primário ou legislativo, das normas gerais, criadas pelos ótgãos autorizados pela Constituição a elaborar as leis, e que na Constituição tến sea fundamento de validade, condicionando, por sua vez, nesse nível intermediário, as normas da base do ordenamento; $e$

(c) o grau secundário, composto das normas individuais criadas em nivel concreto, via processo judicial (decisões judiciais) e via procedimentos adiministrativos (resoluções administrativas), com seu fundamento nas normas de nível primátio.

A classificação tradicional das funções juridicas do Estado, desenvolvida desde o século XVIII, centra-se na contraposição dos conceitos de legislação (função de criação de direito ou função legislativa) e de execução (função executiva e função judiciária), como se essas pudessem ser separadas entre si e sobre um plano horizontal de paridade. KELSEN revolucionou os termos de tal equação, minimizando a importância da separação entre legislação (criação de nomas) e execução (em sentido lato). Essa distinção apenas indicaria a posição que as normas 'gerais' (leis) e as normas 'inclividuais' (sentenças e atos administrativos) ocupam na dinâmica do ordenamento.

Assim, para KELSEN, todas as normas de um ordenamento são, ao mesmo tempo, normas de criação e normas de execução do direito. Un ato criador de direito novo (uma lei, por exemplo) está, ao mesno tempo, sempte e necessariamente, executando a norma hierarquicamente superior, na qual se fundamenta seu poder de criação. Excluem-se dessa conjugação entre criação e execução somente dois casos limites: (a) no topo mais elevado da pirâmide, a norma criadora da primeira Constituição, que é apenas norma de criação de direito, pois ela não se fundamenta em nenhuma nomma jurídica anterior (mas apenas no pressuposto racional hipotético e fundamental de que a ordem deve ser obedecida); e (b) na base, a execução de uma norna-sanção, em um caso concreto, é apenas um ato de execução, pois se traduz em simples obediência ao direito, sen criar nenhuma norma jurídica que the seja inferior. ${ }^{8}$

Essa visão de KEILSEN veio a se tornax clássica no mundo cultural romano-germânico. Essa doutrina fundou, nas primeiras décadas do século XX (com a constituição de Weimar), o direito constitucional efetivamente jurídico, ou seja, um verdadeiro direito - na verdade o direito fundamental - hierarquicamente superior ao restante das normas jurídicas do ordenamento. Não esqueçamos que até o primeiro pós-guerra, com a exceção dos Estados Unidos e dos países seguidores, o direito da Constituição era um direito político, ou seja, sem natureza ou eficácia jurídica próprias.

O próprio KEISEN completaria essa revolução, erigindo uma teoria e uma técrica de controle de constitucionalidade adequadas à cultura romano-germânica.

* KELSEN, Hans, Teoria General del Derecho y del Estado, pp. 146-155. 


\section{O ORDENAMENTOJURÍDICO SOB UMOLHAR TELEOLÓGICO}

Nunca será demais realçar a importância do pensamento e das construções institucionais de KELSEN para o direito constitucional contemporâneo. Ele está para o Estado Social contemporâneo como MONTESQUIEU para o Estado Liberal Clássico. Isso, porém, não nos impede de apontar os limites de sua concepção. O principal deles foi o de reduzir o ordenamento jurídico a uma cstrutura exclusivamente lógica, vedando qualquer abettura ao plano teleológico ou finalistico.

Ensinavam os clássicos que o direito está, como a ética e a política, no domínio da razão prática. Os seres humanos, vivendo em sociedade, são capazes de contemplar os fins últimos da convivência (o telos), a partir do ponto de inserção social em que cada um se encontra. Dessa contemplação, cada qual vê o telos de sua perspectiva, como lhe parece (o bem aparente). Essas visões diferenciadas articulam-se en formas diferentes de interpretação (arché), a serem confrontadas umas com as outras no denominado processo deliberativo, que deve ser o mais aberto e plural possivel, via instituições adequadas. O pano de fundo das interpretações e do processo deliberativo há de ser a realidade concreta. A deliberação emerge do diálogo entre o telos, suas diversas interpretações, bem assim a realidade dos fatos. Da deliberação resultam as decisões, traduzidas, afinal, em ações concretas."

A razão prática opera, assim, por um silogismo prático em que a premissa 'maior' é o bern ou o fim contemplado, sujeito às interpretações do bem aparente; a premissa 'menor' está nas situações de fato; a conclusão vem a ser a decisão e a ação. ${ }^{10}$

O ordenamento juridico pode e deve ser olhado teleologicamente. Em nivel mais clevado eabstrato estão os valores jurídicos, o verdadeiro telos do direito, o direito enquanto válores fundamentais do convivio sócio-político. Em nivel intermediátio dá-se o processo deliberativo: a sociedade, mediante instituições políticas, inspirada nos valores jurídicos fundamentais, interpretados segundo linhas ideológicas historicamente situadas, extrai, dialogalmente, frente às situações concretas da vida, decisões que fixam normas gerais que haverão de regular o convívio na polis. Em nivel concreto, os operadores do direito, mormente a administração e o judiciátio, agem concretamente na sociedade, prestando serviços e resolvendo conflitos.

A evolução político-jurídica do Ocidente chega ao século XXI reconhecendo uma estrutura funcional de ordenamento jutídico em que podemos divisar três niveis de direito positivo: $1^{0}$ ) o nível fundamental que, alćm de estabelecer o quadro da organização política básica do Estado, contempla os valores jurídicos superiotes, boa parte deles formulados como direitos ditos fundamentais, o nivel do direito constitucional; $2^{\circ}$ ) o nível intermediário

? Una boa descrição de como opera a razấo prática em ARISTÓTELES está em Alasdair MACrNTYRE, Justiça de quem? Qual Racionalidade? São Paulo, Loyola, 1991, Cap. VII, pp. 139-160.

10 MACINTYRE, op. cit., p. 155. 
onde está o direito ordinário, seja ele público ou privado, vale dizer, o conjunto de todas as normas gerais que, frente ì realidade, procuram operacionalizat os valotes e os direitos fundamentais essenciais ao convivio interpessual; $3^{\circ}$ ) o nível concreto, o direito realizado, nos fatos da vida, pelos administradores e pelos juízes, cujo segmento mais importante poderíamos denominar de direito judiciátio.

\section{ENTRE A LÓGICA EA TELEOLOGIA}

O olhar lógico e o olhar teleológico do ordenamento jurídico não se contrapõem; antes, complementam-se. Ambos confluem naqueles três planos sucessivos, que, em correntes ascendente e descendente, sobem e descem do geral e mais abstrato, ao particular $\mathrm{e}$ mais concreto.

Diferenciam-se em que, na perspectiva lógica, o ordenamento sugere a rigidez eo peso do método dedutivo. Ou seja, o ordenamento seria uma cadeia de comandu, dotada de força imperativa, a descer de cima para baixo, enquadrando e conformando os níveis que somos tentados a considerar "inferiores" do ordenamento. A tentação al estaria numa certa "idolatria" ao direito constitucional. Já na perspectiva teleológica prevalece a idéia de plasticidade do ordenamento. É da realidade, da essência mais profunda da vida social, que brotam os grandes valores jurídicos. A mediação entre a tealidade e os valores - feita no plano das ideologias, da deliberação, do diálogo — revela então toda a sua importância. A tentação passa, então, a ser a "idolatria" do empírico, do ideológico, do direito judiciátio.

Uma visão equilibrada e realista do ordenamento juridico há de procurar conciliar, numa unidade, as duas perspectivas, atenta ao continuo evolver do espírito, empurrado pelo incessante fluir da realidade. Dessa confluência de perspectivas, muitas questöes difíceis com as quais hoje se confrontam os juristas podem vir a ser resolvidas, especialmente aquela das relações entre o direito constitucional, o direito ordinário e o direito judiciário.

\section{O DEBATE ATUAL: O AVANÇO DEUMEQÜT́VOCO ESUA CRÍTICA}

As relações entre direito constitucional, direito ordinário e direito judiciário vêm ganhando, assim, importância capital. A questão começou a ser ventilada, no estádio atual da teoria do direito, na Alemanha, com muito equilíbrio. Em 1984, veio à luz ensaio pioneiro de C.-W. CANARIS, focado sobre os direitos fundamentais. " O tema, com un escopo mais geral, foi enfrentado por K. HESSE en $1988.1^{12}$

"Oensaio tem o titulo de Direitos Fundanentais e Direito Privado (publicado em Archio für civilistische Práxis, r. 184, 1984, pp. 202 e ss.). O tema, atualizado e ampliado por CANARIS, está traduzido para o português, em obra do mesmo título, editado em Coimbra, pela Almedina, em 2003.

12 HESSE, Konrad. Derecho Constitucional y Derecho Privado. Madrid, Ed. Civitas, 1995,88 pp.. 
No Brasil dois fatores vão acender e alimentar a discussão: $\left.1^{\circ}\right)$ A Constituição de 1988 estendeu sua matétia normativa, inclusive sobre o direito privado, como o atesta o capítulo sobre a familia, a criança, o adolescente e o idoso; e $2^{\circ}$ ) O novo Código Civil abriu ainda mais o sistema jurídico brasileito a cláusulas gerais e a conceitos indeterminados. ${ }^{13}$ Essas preocupações não têm escapado dos juristas argentinos. ${ }^{34}$

Nesse debate, do pluralismo saudável dos posicionamentos, vem se articulando uma corrente a nosso ver equivocada e - como veremos a seguir- desbordante do Estado democrático de Direito. Referimo-nos à opinião que propaga, sem devidas cautelas e necessárias ressalvas, a "constitucionalização (direta e imediata) do direito ordinário", inclusive, do direito privado. Nessa visão, entre direito constitucional e direito ordinátio não haveria distinções de funções, nem, pois, de âmbitos de legítima autonomia. Para esse "novo constitucionalismo" não caberiam limites à intervenção das normas constantes do texto constitucional (máxime as que contemplam princípios) relativamente aos demais subsistemas de normas existentes no ordenamento.

Essa corrente parte da distinção topográfica entre as normas inseridas no texto constitucional e as demais normas esparramadas nos textos legislativos ordinários. E, furmada essa distinção, determina uma submissão completa, direta e imediata, do direito ordinário àquilo que os seus propagadores entendem dever ser considerado direito constitucional. Essa corrente bem poderia ser denominada de totalitarismo jurídico, ou de colonialismo do direito constitucional sobre os demais ramos do direito.

Falta totalmente a essá corrente uma visão integrada do ordenamento jurídico, capaz de contemplar a unidade superior que conjuga pelo menos três instâncias (direito constitucional, direito ordinátio e direito judiciário), com funções lógicas e teleológicas distintas e complementares, dignas do devido respeito, num tecido de relações recíprocas ascendentes e descendentes. Falta totalmente a essa corrente a compreensão de que o fundamento do direito (a dignidade da pessoa humana, com todos os seus valores) não foi pendurado por uma vontade política constituinte no ápice da pirâmide jurídica, para de lá ditar seus comandos. O fundamento do direito está, isso sim, nos alicerces do ordenamento, ou seja, na realidade ontológica da pessoa, da família e da vida social ordinária. Daí vai subindo, em instâncias criticas e de diálogo, pela via do direito legislado, até a cúpula do ordenamento, de onde, enriquecida e descortinando o todo, pode realimentar o diálogo circular hermenêutico, que recomeça nas bases do ordenamento.

${ }^{13}$ Destacamos, exemplificativamente, Ingo W. SARLLET (Org), A Constituição Concretizada, P. Alegre, Livraria do Advogado, 2002; Gustavo TEPEDINO (Org.), Problemas de Direito Civil Constitucional, RJ, Renovar, 2000, 577 pp; Judith MARTMNS-COSTA, A Reconstruçäo do Direito Privado - Reflexo dos princípios, diretrizes e direitos fundamentais constitucionais no Direito Privado, SP, RT, 2000.

${ }^{14}$ Cf. Carlos A. MAYÓN, Bases Constitucionales del Derecho Civil, La Plata, Rd. I.ex, 2001, 352 pp. 


\section{FATOR INSTTTUCIONALDOEQÜT́VOCO}

Dentro de um quadro causal plural e complexo, há, a nosso ver, um fator institucional que muito favorece, no Brasil, o avanço do totalitarismo constitucional. No nivel político, a fusão dos três níveis das funções políticas (Estado, Governo e Administração), no órgão unipessoal do denominado poder executivo. E, no âmbito do direito $\rightarrow$ o objeto deste estudo - a fusão, no mesmo órgão (o poder judiciário), da jurisdição ordinária e da jurisdição constitucional (monismo jurisdicional). ${ }^{15}$

O monismo jurisdicional, combirado com a mentalidade constitucional totalitária, tende a produzir uma concentração de poderes no poder judiciátio ordinátio, já bastante estudada em direito comparado. ${ }^{16}$

Passaremos a aprofundar três pontos que mostram a essencialidade, para o Estado democrático de direito, de uma adequada relação entre os três planos do ordenamento jurídico.

\section{ESTADO DE DIREITO, VALORES EIDEOLOGIAS}

O Estado de Direito emerge do segundo pós-guetra sobre um quadro mínimo e básico de valores, decorrentes todos da dignidade única e preeminente da natureza humana. Ei-los: a liberdade (primeiro deles), que se ajusta à igualdade pela justiça, perdura no tempo com a segurança e implica um equilíbtio entre ordem e progresso.

Lembremos, desde logo, que os valotes nascem da realidade fática profunda da dignidade humana e, descobertos e trabalhados pela razão, assumem uma dimensão metafísica (geral, abstrata e universal). Para serem re-concretizados nos fatos, pelo direito, têm de passat, necessariamente, por um processo de mediação. Ao cruzarem a fronteira entre os planos, os valores deixam de ser valores (gerais, abstratos e universais) e inevitavelmente contaminam-se dos interesses e das ideologias que envolvem a vida humana concreta. Ou seja: os valores enquanto valores só existem no plano fundamental do ordenamento jurídico. Toda concretização, seja no plano intermediário da lei, ou no plano concreto dos fatos,

Is Como mostramos em outro lugat (A Supremacia do direito, P. Alegre, 2002), somente no common law podem ser fundidas sem problemas as duas jurisdiçôes (a ordinâria e a constitucional), pois naģuela cultura há uma separação bistórico-sociológica entre direito on jurisdictio (a cargo dos juizes) e política ou gubernaculum (a cargo do Congresso e do Parlamento). (Sobre a distinçẫo encre jurisdictio e gubernaculum Chatles MCILWAIN, Constitutionalism Ancient and Moderns, London, Cornell UP, 1940). Em cultura romano-germânica, a primeira fonte do direito é a lei (cabe ao poder legislativo a competência juridica de nivel primáxio), de modo que a atribuiçào ao Judiciário, além da jurisdiçầo legislativa ordinária, a dá jurisdição constitucional, imbrica no sistema jurídico uma contradição, um conflito invencível.

16 Ver Karl LOEWENSTEN, Teoria de la Constitución, Batcelona, Ariel, 1970. pp. 310 e ss.. 
envolve, ainda que em grau mínimo, uma ideologização. ${ }^{17}$ Por isso JELLINEK ${ }^{18}$ ensinava que os valores da Constituição não nos servem para dizer o que fazer: essa tarefa direta e imediata é ideologizante e, pois, tequer necessariamente órgãos políticos de legiferação; a função dos valores é de controle (ou seja, indireta e mediata), supondo a preexistência de uma legislação a ser examinada, a ser corrigida, a ser "julgada".

Essa, a primeira e grande razão para a preservação da autonomia (legítima, equilibrada e moderada) entre as funções de direito constitucional e as de direito ordinário. Sem o respeito àquelas exigências da razão prática e da realidade, o direito constitucional deixaria de ser um direito de valores para ser um direito de ideologias e de ideologias da pior espécie: daquelas que se disfarçam sob a pele de valores.

Para garantir a transcendência do plano constitucional dos valores, todos os países de tradição tomano-germânica na Europa, sem exceção, instituítam uma jurisdição constitucional distinta da jurisdição ordinária. Não foi, pois, por acaso que o constitucionalismo de valores do segundo pós-guerra trouxe com ele o denominado Tribunal Constitucional como poder autônomo do Estado. ${ }^{19}$ A separação das duâs Justiças passou a ser um dos arranjos essenciais do Estado democrático de Direito.

\section{ESTADO DE DIREITO E A INSTÂNCIA DE SOBREDIREITO}

A descoberta do direito em concreto e o aprimoramento constante das instituiçóes requerem um permanente diálogo entre tealidade, direito legislado e direito enquanto expressão dos valores humanos mais elevados. No Ocidente, da baixa Idade Média até o surgimento do constitucionalismo contemporâneo, o cultivo do direito justinianeu pelos professores da Universidade, operava como esse verdadeiro sobredireito. Tal função crítica dialógica do direito codificado era cumprida formalmente dentro do próprio direito civil. A autonomia dos comentadores e dos professores for sempre apreciada e estimulada como essencial ao progresso do direito na direção da realização de uma justiça melhor, mais próxima do ideal.

O diteito constitucional, surgindo no Séc. XVIII, passou a atrair, para sua esfera, progressivamente, a função de sobredireito, num primeiro momento sob color de "irradiação" da liberdade no plano do direito ordinário (inclusive no direito privado). Depois, no segundo pós-guerra, a Constituição, ao abraçar, além da liberdade, uma constelação de valores, franqueou um campo riquíssimo ao sobredireito, o qual só é sobredireito na medida em qué respeita e preserva o direito legislado. É nele que o sobredireito encontra o interlocutor válido para cumprir sua função e para realizar, de forma mais elaborada, a Justiça. A absorção do direito ordinário pelo direito constitucional, com efeito, suprimiria o sobredireito, afetando a própria essência do Estado democrático de Direito.

"É o que nos ensinam os clássicos da razão prática (v. Alasdair MACINTYRE citado).

is Op. cit.; PP. cit.

19 Cf do Autor O Tribunal Constitucional como Poder (S.Paulo, Memória Jurídica, 2002). 


\section{ESTADO DE DIREITO E A SUBSIDIARIEDADE DE NÍVEIS DO ORDENAMENTO}

Nas sociedades políticas mais antigas, de extensão territorial reduzida, o chefe único, que acumulava poderes "jurídicos" e cuidava da ordem social, exercia, antes de tudo, a composição e o julgamento dos conflitos. Esforçava-se por progressivamente substituir as práticas desagregadoras da vingança privada. Assim, a primeira função juspolítica dominante a se organizar em tomo do poder parece ter sido a judicial. ${ }^{20}$

Com a evolução e a complexificação crescentes da vida social, os juizes sozinhos não podiam mais atender adequadamente a necessidade generalizada de orientação das condutas na comunidade. Só então aparece a aspiração social e política por pautas objetivas para dirigir o comportamento social, na direção do bem comum. Surgia assim o legislador, atuando sobre o direito em um nivel de abstração e de generalidade mais elevados, com as primeiras leis escritas. O progresso trouxe não somente a sofisticação dos juizados individuais e coletivos (os tribunais), mas principalmente a modernização das tarefas e dos instrumentos legiferantes.

Prosseguindo a trilha evolutiva, as necessidades de limitar os poderes juspoliticos e de garantir a liberdade dos membros da comunidade, conduziram a sociedade - no início pela via revolucionária - à descoberta do poder constituinte e à adoção de Constituições escritas. A consciência jurídica, então, avançou ainda mais, passando a demandar a fiscalização da obra do legislador. Criaram-se, então, técnicas de controle de constitucionalidade das leis, culminando, na segunda metade do século XX, na Europa Continental, com a instituição de um novo poder político, o Tribunal Constitucional, formado de juízes constitucionais.

Dessa linha evolucionária da história institucional das funções jurídicas do Estado podemos extrair dois princípios: (a) o da especialização crescente dos órgãos sociais e políticos; e (b) o da subsidiariedade das funções sociais e políticas. Não é aqui o lugar de aprofundar o princípio de letra (a). Já o princípio de letra (b) nos sugere alguns pontos muito importantes para os objetivos do presente trabalho.

Primeiro: a mais importante das funções jurídicas é a de juiz. É, existencialmente, o ponto de partida de toda a atividade juridica, sem a qual nenhuma das demais poderia operar. É a que está mais próxima do fundamento ontológico do direito, ou seja, a pessoa humana, real e viva, com sua preeminente dignidade ao mesmo tempo individual e social, livre e solidária, corporal e espiritual, dotada de direitos e deveres fundamentais e vocacionada a um mundo de valores superiores que ao direito cabe garantir e promover. É a que vai servir diretamente a pessoa humana necessitada da tutela jurídica, o sujeito primeiro e a finalidade

26 As fontes biblicas nos falam que o governo primitivo dos hebreus foi dos juizes. No Ocidente Medieval, o common law é anterior à recepção da codificaçào de Justiniano e sua primeira característica éa de ser um judge made law. 
última de todo o ordenamento jurídico. O ordenamento asseguta à função judicial um espaço próprio de autonomia, inclusive para colmatar lacunas, pela via da equidade e dos princípios gerais do direito. Em seguida, e na ordem, seguem-lhe, em relevância - pelas mesmas razões - a função legislativa e a função de controle constitucional, respectivamente.

Segundo: cada nível funcional, enquanto as condições sócio-culturais não cobravam especialização, realizava subsidiariamente as tarefas de nivel mais abstrato. Assim, no periodo primevo, o juiz que judicava cumpriá, embrionariamente, também, a tarefa de legislador (pelos precedentes gerava normatividade) e, ainda mais, implicitamente, era o controlador dos valores superiores daquele direito rudimentar.

Terceiro: mesmo nos Estados mais evoluídos, a precedência ontológica (primeiro ponto) e a preferência subsidiária (segundo ponto) subsistem e continuam a valer em prol dos niveis mais concretos do ordenamento. Assim, não é tanto o juiz, enquanto juiz, que existe para servir os legisladores; antes, as legislações é que existem para ajudarem o juiz a fazer Justiça no caso concreto. Também não é tanto a legislação que existe para fazer a grandeza ou preservar eficácia das constituiçôes; antes, as constituições é que foram inventadas para defender, proteger e amparar as boas legislaçôes, aprimorando, corrigindo e suprindo as defeituosas.

Enfim, as constituiçôes não deven, nem podem, pretender substituir, jugular ou mesmo abafar as legislações, nem estas a juizes realmente juízes. Práticas e doutrinas com tal pretensão seriam verdadeiras monstruosidades totalitárias, a subverter a dignidade humana (o fundamento de todo o direito), e a distorcer os valores fundamentais do ordenamento juridico (as autênticas aspirações da dignidade humana, finalidades de todo o direito).

\section{CONCLUSÃO}

Observados os princípios da precedência ontológica e da preferência subsidiária, as rclações entre os niveis ou planos do ordenamento jurídico pedem obediência às legítimas autonomias de cada qual è̀ complementaridade entre cles. É neste quadro de relações que devem ser examinadas as numerosas questões tópicas envolvidas na matéria, como, por exemplo, a tormentosa questão dos efeitos dos direitos fundamentais sobre o direito ordinário em geral e o direito privado em particulat.

O presente texto procurou expor, em consonância com as últimas pesquisas do Autor, a doutrina universal, a qual tem procurado guardar fidelidade aos postulados da tradição ocidental do Estado democrático de direito. Essa doutrina, amplamente majoritária na Alemanha, está deduzida no ensinamento abalizado de seus maiores juristas, como E. FORSTHOFF, K. HESSE E C. W. CANARIS.

A Constituição, escrevia o primeiro, não é um supermercado donde se possam satisfazer todos os desejos, nem deve ser transformada em uma massa de argila nas mãos dos ideólogos. ${ }^{2 i}$ Por sua vez, anotou HESSE, "a Constituição é a ordem jurídica fundamental 
da Comunidade. Entretanto, de forma alguma regula tudo, mas somente aspectos singulares - geralmente os particularmente importantes - da vida estatal e social, abandonando o resto da configuração aos poderes estatais por ela constituídos, em particular ao legislador democrático. Por isso, o significado do Direito Constitucional para o diteito privado consiste em singulares funções de garantia, orientação e impulso." 22 Mostra HESSE, não só a importância do direito constitucional para o direito ordinário (e o privado em especial), mas o inverso, a importância do direito privado para o direito constitucional. Suas palavras são tão aptopriadas, que as escolhemos para encerrar este trabalho:

"Antes de tudo, um Direito Civil que descanse sobre a proteçăo da personalidade e sobre a autononia privada forma parte das condiçôes fundamentais da orčem constitucional da Lei Fundamental. A liberdade privada da Pessoa, que o Direito Civil pressupõe e para cuja preservação e desenvolvimento põe normas e processos jurídicos, é requisito indispensável para as decisões responsáveis e, mesmo, para a possibilidade dos atos de decisão. Isto tudo fundamenta a enorme transcendência do Direito Privado para o Direito Constitucional. Na autodeterminação e na própria responsabilidade da Pessoa se manifesta, em parte essencial, a natureza da Pessoa na qual se funda a própria Lei Fundamental e da qual depende a ordem constitucional."23/

${ }^{21}$ FORSTHOFF deixa bem claro que "a subordinação do legislador à Constituição é bem diferente da vinculação completa, como se a Constituiçăo fosse a origem do mundo, uma célula juridica germinal da qual tudo deve proceder, desde o Código Penal a una lei sobre termômetros." (El Estado de la Sociedad Industrial, Madrid, IEP, 1975, pp. 241-242).

${ }^{22}$ HESSE, Konrad. Derecho Constitucional y Derecho Privado. Madrid, Civitas, 1995, p. 82 e ss.

${ }^{23}$ Op. cit. p. 86. 


\section{REFERÊNCIAS BIBLIOGRÁFICAS}

BOBBIO, Norberto. A Teoria do Ordenamento Jurídico. Brasilia, UnB, 1995, 184 pp.

CANARIS, Clausw Withelm. Direitos Fundamentais e Direito Privado. Coimbra, Almedina, 2003, 167 pp.

FORSTHOFE, Ernst. Estado de la Sociedad Industrial, Madrid; IEP, 1975, 289 pp..

JELLINEK, Georg. Teoria General del Estado. Buenos Aires, Albatroz, 1971, 602 pp.

KELSEN, Hans. Teoria General del Derecho y del Estado. México, UNAM, 1969, $478 \mathrm{pp}$.

KELSEN, Hans. Teoria Pura do Direito. Coimbra, Armênio Amado, 1979, 484 pp..

HESSE, Konrad. Derecho Constitucional y Derecho Privado. Madrid, Civitas, 1995.

LOEWENSTEIN, Karl. Teoria de la Constitución, Barcelona, Ariel, 1970.

MACINTYRE, Alasdair. Justiça de quem? Qual Racionalidade? São Pâulo, Loyola, 1991, $440 \mathrm{PP}$.

MARTINS-COSTA, Judith. A Reconstrução do Direito Privado - Reflexo dos princípios, diretrizes e direitos fundamentais constitucionais no Direito Privado. São Paulo, RT, 2000.

MC ILWAIN, Charles H., Constitutionalism Ancient E Modern, London, Conell Universiy Press, 1940, 180 pp..

MAYÓN, Carios A.. Bases Constitucionales del Derecho Civil. La Plata, Ed. Lex, 2001, $352 \mathrm{pp}$.

SARLET, Ingo W. (Org). A Constituição Concretizada. P. Alegre, Livtaria do Advogado, 2002.

SOUZA JUNIOR, Cezar Saldanha. A Supremacia do direito e seus Modelos Básicos, P.Alegre, do Autor, 2002.

O Tribunal Constitucional como Poder. São Paulo, Memótia Jurídica, 2002.

TEPEDINO, Gustavo (Org). Problemas de Direito Civil Constitucional. RJ, Renovar, 2000,577 pp..$^{24}$

24 Escreveu John LOCKE: "In the Infancy of Government, (...) the Government was almost all Prerogative:" Two Treatises of Government, London, $1690, \$ 162$, linha 6 . 